\title{
Mass Tourism Underwater: A Segmentation Approach to Motivations of Scuba Diving Holiday Tourists
}

\begin{abstract}
Scuba diving is an increasingly popular activity in resort destinations worldwide, providing tourists a more active experience in their holiday. By following the Push and Pull Theory, this study examines the scuba diving motivations of holiday tourists. Whilst of substantial importance for the practice of the activity, host marine destinations and broader ocean literacy, this an under-researched topic in the tourism literature. Data were collected from a comprehensive data set of holiday tourists who participated scuba diving in Kemer, AntalyaTurkey. Exploration \& excitement, personal development, and socialisation \& challenge were identified as the push motivations, while tourism \& diving offerings, safety \& accessibility, ancillary attributes, new area, and unspoiled diving destination were determined as the pull motivations. Moreover, cluster analysis revealed four groups who had various motivations to participate scuba diving, namely Enthusiastic Positivists, Youthful Hedonists, Amateur Explorers, and Single Regulars. Findings of the research were discussed along with their theoretical and managerial implications.
\end{abstract}

Keywords: holiday tourists; scuba diving; push and pull motivations; market segmentation; Kemer, Antalya

\section{Introduction}

Tourism literature shows that positive experiences in destinations may generate tourist satisfaction and re-visit intention. In resort destinations, tourists are increasingly seeking to have more active experiences, such as marine-based activities (Sung, 2004; Morgan, Moore, \& Mansell, 2005, Cater and Cater, 2007). One of the marine-based activities that has seen growing popularity is SCUBA (Self Contained Underwater Breathing Apparatus) diving, which firstly emerged as a niche market. With the influences of changing social trends and developments in modern equipment, scuba diving has become a mass tourism activity in recent years (Dimmock, 2009) with significant implications for marine places. Since 1967, PADI, the leading diver certification agency, has issued over 27 million diver certifications (PADI, 2019), representing a multibillion dollar industry worldwide (Musa \& Dimmock, 
2012), much of it centred on coastal tourist resorts. For example scuba diving is a central activity in ocean-based tourism and recreation contributing some \$124 billion in GDP to the US national economy alone each year (NOAA, 2019).

A review of scuba diving literature reveals that researchers have mostly investigated its effects on marine life (Bradley, Papastamatiou, \& Caselle, 2017), especially on coral reefs (Barker \& Roberts, 2004). Scuba diver injuries have been another leading concern of researchers (Wilks \& Davis, 2000; Taylor, O’Toole, \& Ryan, 2003). However, as highlighted by Garrod and Gossling (2008), relatively few studies in the tourism literature have examined scuba divers' motivations (Meisel-Lusby \& Cottrell, 2008; Fuchs, Reichel, \& Shani, 2016). Early research of Rice (1987) categorized scuba divers into three groups as 'hard core', 'tourist', and 'potential', claiming that they have distinct motivations. However, the majority of previous studies tended to focus on the professional scuba divers categorised as 'hard core' by Rice (1987). Furthermore, there is limited research that investigates the motivations of holiday tourists who participate in scuba diving during their vacation. Whilst industry statistics show that this market has become increasingly popular, these tourists represent a separate market segment that has had limited exploration by researchers.

The Push and Pull Theory in the tourist motivation literature, first proposed by Dann (1977), may assist researchers in understanding which push (demand-side; tourist-specific, intangible, and intrinsic desires) and pull (supply-side; destination-specific, tangible, and extrinsic attributes) motivations are prevalent for tourists who dive during their holiday. Although, the Push and Pull Theory has been widely used in different areas such as national parks (Kim, Lee, \& Klenosky, 2003) and rock climbing (Caber \& Albayrak, 2016), it has not been explicitly tested on tourists who dive in resort destinations.

The aims of the present novel study are, therefore, (1) to describe tourists' demographics who participate in scuba diving activity during their holiday and their scuba diving-related characteristics; (2) to identify push and pull motivations of these tourists; (3) to cluster tourists relying on their scuba-diving motivations; and (4) to clarify the profile of the obtained clusters. The present study advances the literature by investigating scuba diving motivations of holiday tourists with the use of push and pull motivation framework. In addition, the study provides empirical evidence that holiday tourist' motivations show differences in participating in scuba diving. The study results are also beneficial for scuba diving companies and destination marketing organizations in segmenting tourists who dive during their holiday 
based on their motivations. The obtained findings may enable the authorities to design tailored services that may meet holiday tourists’ needs.

In this study, for achieving the research objectives, data were obtained from tourists visiting the resort destination of Kemer, situated in Antalya province, Turkey. Kemer was chosen as the research area since it has received little scholarly interest, despite its importance for scuba diving tourism in Turkey. In the following section, a summary of the literature on scuba diving tourism and participant motivations are provided. Following this, the study method and the results of the analyses are presented. The paper concludes with discussion of the results, study limitations, and future study recommendations.

\section{Scuba diving in tourism and motivations of the participants}

With tourists continuing to seek new and challenging experiences provided by activities such as scuba diving, there has been an increase in both the number of tourists who are scuba diving and the number of dive destinations. The number of amateur divers in particular has increased exponentially over the past two decades (PADI, 2019). The current annual growth rate of the dive travel market is estimated to reach $16 \%$ worldwide and the most important source markets for diving tourism are identified as the USA, Italy, Germany, France, and the UK (CBI, 2019). Whilst scuba diving was once seen as a niche activity, it is now a popular tourist activity offered in many coastal tourism resorts. This is evidenced by the over a million new certifications authorised by PADI every year (PADI, 2019). New markets have been important in this growth, with emerging economies such as Turkey and Russia showing significant interest in scuba diving activity. In line with new markets, emerging destinations with marine tourism product have sought to maximise the opportunity for scuba diving through investments in supporting infrastructure. For example, Malta has scuttled a number of wrecks and developed entry facilities around the islands since identifying this opportunity in the 2006 national tourism plan (Garrod \& Gossling, 2008, Bideci and Cater, 2020). Given the preference of diving tourists for warmer water destinations much of this growth in these regions has been at the expense of destinations in cooler places. For example, diving numbers at Skomer marine reserve, Pembrokeshire, Wales, a cooler, temperate dive location, have halved over recent decades (NRW, 2017).

There is, therefore, an inextricable link between scuba diving and tourism for many participants. However, Garrod and Gossling (2008) highlight some of the difficulties in 
defining scuba diving tourism, noting that the 'degree to which going diving forms part of an individual's travel motivation tends to vary considerably'. Whilst some individuals plan holidays exclusively around scuba diving, much of the recent growth in dive tourism is attributed to those who 'intend to dive only when diving conditions are particularly favourable or when they have no other leisure activities planned for the day' (2008:5). These tourists who dive during their holiday have been termed resort divers (Davis \& Tisdell, 1995) or sideliner divers (WTO, 2001). Hence, this study follows Garrod and Gossling's (2008) definition of diving tourists being all those undertaking one or more diving activities whilst travelling from their usual place of residence, even if this is not a primary motivator or activity.

As noted above, although early studies on scuba diving focused largely on economic and environmental impacts and management (Garrod \& Gossling, 2008), there is now some awareness regarding the motivations of scuba divers (Todd, Graefe, \& Mann, 2002; Musa, Kadir, \& Lee, 2006; Dearden, Bennett, \& Rollins, 2006; Cater, 2008; Dimmock, 2009). Wong, Thirumoorthy, and Musa (2013) provide a review of motivational research in scuba diving, noting work on internal and external motivations, diver profile, location, specialisation, and gender attributes. Ong and Musa (2012) have suggested principal motivations include 'experiencing underwater flora and fauna', 'exploring new things', 'experiencing the adventure of diving', 'having stimulating and exciting experience', and 'learning about the underwater environment'. Similarly, Cater (2008) illustrated the application of Beard and Raghebs (1983) leisure motivation model to scuba divers, presenting a qualitative examination of motivational push categories of 'education', 'esteem', 'expertise', 'escape', and 'embodiment'. The multisensory engagement afforded by this last category is an important motivator for experiential tourism, particularly in marine settings (Cater, 2010).

A variety of other motivational studies have been conducted with professional scuba divers, many in specific geographic locales, with a dominance of coral reef settings. The majority of studies have been carried out with tourists who have a higher level of commitment to scuba diving and possess a level of diver certification. However, diving experiences of holiday tourists, particularly in the Mediterranean, do not take place in a coral environment, and often involve no qualification. Elsewhere these holiday divers have been termed 'tea bag' divers by operators (Garcia, 2018), as they are only interested in a quick immersion and look for safe and comfortable diving experiences with limited 'sense of place'. However, as scuba diving has entered the mainstream, there is perhaps less awareness regarding the types of destination attributes that scuba divers seek, although Dearden, Bennett, and Rollins (2006) note that less 
specialised divers put greater importance on environmental and service factors. These may be designated as pull factors in line with the comments above. However, the underlying pull motivations of holiday tourists to participate scuba diving are still unclear. Furthermore, along with this growth, it is unlikely that tourists who dive during their holiday are homogenous in their needs, preferences, and behaviours.

\section{Method}

\subsection{Research setting}

The study was conducted in Kemer which is situated $43 \mathrm{~km}$ away from Antalya city, in Turkey. It has a population of 44,757 including almost 2,500 foreign residents. The town is one of the most important tourism spots in Turkey with a $52 \mathrm{~km}$ coastline (Kemer Municipality, 2019). Receiving 1.3 million visitors in 2017, Russian tourists constitute the leading market for the destination (Hurriyet, 2018). Owing to blue flagged and long beaches, the destination offers various marine and sports activities to both domestic and international tourists such as mountaineering, trekking, scuba diving, safari, hunting, and yachting. Currently, 20 diving centres are operating in Kemer, under the permission of the Turkey Underwater Sports Federation (Dailysabah news, 2018). Both domestic and international tourists show significant interest in scuba diving at the locations such as Moon Light harbour, Kiriş Bay, Three Islands, Lighthouse, Kiris Cave Bay, Kiriş Aquarium Bay, the Pati wreck, and the Paris II wreck (Figure 1). In addition, Kemer Promotion Foundation (KETAV, 2019) organizes International Kemer Underwater Days every year. According to official estimations, almost 40,000 discovery (amateur) and 20,000 professional dives are performed in Kemer, annually (Turkish Chamber of Shipping, Antalya Branch, 2018). Both winter and summer periods are suitable for diving, however, the high season is between May and September.

Figure 1 here*

\subsection{Measures}


A robust research design implemented the questionnaire used in this study consisting of four main sections. The first section captures five demographic- and four diving-related questions. The second section measures respondents' pull motivations, using a 23 item scale adapted from Woratschek, Hannich, and Ritchie (2007). The third section consists of 25 items that assess push motivations of the respondents, derived from Meisel-Lusby and Cottrell (2008). The last section evaluates respondents' overall satisfaction with their diving experience with three items adapted from Lee, Yoon, and Lee (2007). Seven-point Likert type scale ranging from (1) 'strongly disagree’ to (7) ‘strongly agree' was used to measure the scale items. An English draft questionnaire was translated into German, Turkish, and Russian languages and then checked by bilingual experts to ensure that the meanings of the items were the same across the questionnaires. In addition to this rigour, to ensure wording and translation equivalence, a pilot study was conducted with the participation of 37 scuba divers. The questionnaire used in pilot study also contained two open questions for understanding whether the scale items comprise all possible push and pull motivations for participating in scuba diving. One was for understanding their additional push motivations (i.e. "for what reasons do you participate in scuba diving?”), the other for clarifying their additional pull motivations (i.e. “why did you select this site for scuba diving?”). Based on the pilot study, the authors decided to use the same questionnaire for the field study, since the respondents did not offer any additional motivations for participating in scuba diving. In addition, they did not have any difficulty to understand the scale items presented to them.

\subsection{Data collection}

The data for the study was collected with the collaboration of a scuba diving company that operates in Kemer. A master's degree student, who was trained for the data collection, participated in the scuba diving tours of this company on different days during June 2017. After the diving experience, the interviewer explained the aim of the research to the scuba divers and requested their volunteer participation. At the end of this process, 379 questionnaires were collected. Questionnaires that had consecutive identical answers or that were mostly incomplete were eliminated. This yielded a substantial data set of 308 valid questionnaires for the analysis.

\subsection{Data analysis}


Before the analyses, mean substitution was used for handling missing data (Hair et al., 1998). In addition, normality assumption was evaluated using the statistics of skewness and kurtosis (Appendix 1 and 2). Since these statistics were less than 3 and 10 respectively, normality was not violated in this study (Kline, 2005). Moreover, Cronbach Alpha's values of the push and pull items were respectively 0.913 and 0.907 , reflecting the internal consistencies of the scales.

The systematic analyses consist of four stages. Firstly, socio-demographic and diving characteristics of the sample were clarified. Secondly, exploratory factor analysis was conducted to obtain underlying dimensions of push and pull motivations. Thirdly, cluster analysis was used to segment scuba divers based on their motivations. In the last stage, by using cross-tabulation, cluster characteristics were compared.

\section{Results}

The socio-demographic characteristics of the sample are reflected in Table 1 . The majority of the participants were male (62\%) and single (58.4\%). A significant number of the participants were from emerging economies such as Russia (35.5\%), Turkey (26.4\%), and Ukraine (9.6\%). The majority of the respondents were between 20 and 29 years old, followed by 30-39 years old. In terms of companion, half of the respondents preferred to participate in scuba diving activity with their friends and relatives. Interestingly, the profile of the sample is very close to the approximately 1 million worldwide PADI certifications in 2018, which were 62\% male and 71\% 20 to 39 years old (PADI, 2019).

Table 1 here*

Table 2 presents the travelling and diving characteristics of the respondents. As expected, $78.1 \%$ of the respondents were at a beginner level of development in scuba diving and $64.2 \%$ had no diving experience at all. In addition, more than two third of the respondents visited Kemer, Antalya for the first time. Travel agencies were the most preferred information source (53.6\%) by the respondents, followed by friends and internet. 
Table 2 here*

Two exploratory factor analyses (principal components with varimax rotation) were performed to obtain underlying scuba diving motivations of the respondents, one for push items, the other for pull items. Firstly, exploratory factor analysis was employed on the 25 push items. Six items were excluded from the analysis: four items due to low communalities (below 0.5) and two items due to low item-total correlation (below 0.4). The re-conduction of the analysis with remaining 19 items yielded three factors accounting for $59.99 \%$ of the variance. Obtained factors were named 'exploration \& excitement', 'personal development', and 'socialisation \& challenge' based on the items that loaded on them. Table 3 reflects factor loadings, explained variance, and Cronbach's alpha values as well as mean values for each factor. Cronbach's alpha reliabilities of the factors are higher than minimum requirement of 0.70 , varying from 0.831 to 0.876 . Based on the factor means, exploration \& excitement is the most important push motivation of respondents for participating in scuba diving.

Table 3 here*

The second exploratory factor analysis was conducted by using 23 pull items. Four items that substantially loaded on more than one factor or had low communality were dropped. Factor analysis was replicated with the remaining items. This produced five factors that account for $65.45 \%$ of the total variance. These factors were labelled as 'tourism \& diving offerings', 'safety \& accessibility', 'ancillary attributes', 'new area', and 'unspoiled diving destination', based on highly loaded items. As shown in Table 4, all factor loadings are above than 0.5 and Cronbach’s reliability coefficients are ranged from 0.763 to 0.821 .

Table 4 here*

The non-hierarchical cluster analysis using the K-means algorithm was performed to obtain homogenous segments of the respondents. The push and pull motivation dimensions obtained from factor analyses were used as the segmenting variables. Three to five cluster solutions were examined in terms of their size and interpretability. The four cluster solution was selected, since it was supported by the agglomeration schedule and the dendogram. Moreover, 
a series of variance analysis was conducted to determine to what extent the motivations vary across the segments. Table 5 presents push and pull motivations of the clusters to participate in scuba diving as well as variance analyses’ results.

Table 5 here*

Obtained clusters were named and investigated according to their varying push and pull motivations (Table 5), socio-demographics (Table 6), and diving experience-related characteristics (Table 7). Cluster 1 is named 'Enthusiastic Positivists' in accordance with their push and pull motivations and demographic characteristics. Tourists who are grouped in this category have high arithmetic means both for push and pull motivations. Therefore, they seem very enthusiastic and motivated in performing scuba diving. Tourists in this group put importance on safety \& accessibility (mean 6.25); tourism \& diving offerings (mean 5.67), and ancillary attributes (mean 6.07) in a destination. That shows the positive approach of these people, as they consider the professional diving tourism services and safety issues in the destination that they visited. In summary, Enthusiastic Positivists are scuba diving tourists, who look for professional and controlled diving tourism performances in the destinations and are highly motivated by almost all intrinsic and external motivation factors. Enthusiastic Positivists represent 33.4\% of the total sample. They are young to middle-aged (between 2039 years, in total $84.8 \%)$ single (54.9\%) male (59.4\%) in the majority, whose travel companions are friends and relatives (53.4\%). They are mostly from Russia (28.6\%), Turkey (26.5\%), and the UK (10.2\%). In terms of diving characteristics, they have some advanced (8.8\%) and expert (4.9\%) divers, compared to other groups. In addition, a significant share of the respondents in this group (21.6\%) visited the destination three or more times.

Cluster 2, which represents $15.9 \%$ of the sample, is named 'Youthful Hedonists', since they have some diversifying characteristics from other groups such as being younger, single (70.8\%), but often accompanied by friends and relatives (51.0\%) in their holiday. Although they do not have high intrinsic motivations about: personal development (mean 2.93) or socialisation \& challenge (mean 2.67), they seem curious in exploring a new area (mean 5.72) and feeling exploration \& excitement (mean 5.61). They prefer to dive for seeing and learning new things for their social groups; but not for socializing with new people or developing their diving skills. Half of the Youthful Hedonists are Russian tourists (49.0\%), followed by Turkish (22.4\%), and Ukrainian (12.2\%). They are mostly between 20-29 years 
old (58.3\%). In addition, more than three quarters of the Youthful Hedonists (75.6\%) are first time visitors who mostly prefer internet as their information source (46.9\%).

Cluster 3 is called 'Amateur Explorers', mainly because this group of tourists has the highest share of beginner divers (83.5\%), and who had no previous diving experience (76.7\%). In contrast, these tourists seem highly 'pushed' by exploration \& excitement (mean 6.23) motivations; and 'pulled' by safety \& accessibility (mean 6.11) and new area (mean 6.00) motivations. They prefer to dive in Kemer as a developed diving destination which offers them a safe, easy to access, and different area to explore. Since this group does not have experience in scuba diving, some pull motivations might have played a role in decreasing their perceived risks in diving. Amateur Explorers includes 35.4\% of the participants. They are mostly young to middle aged (between 20-39 years, 76.7\%) male (64.8\%), who are Russian (37.6\%), Turkish (25.7\%), Kazakh (11.9\%), and Ukrainian (10.1\%).

Cluster 4 is named as the: 'Single Regulars', in relation to their more frequent visits to the destination for diving (total second and more time visits, 39\%); greater level of diving experience (intermediate and advanced levels total, 27.6\%); and generally an average level of push and pull motivations. These are mostly the single (65.2\%) males (68.1\%), who are motivated to develop their diving experiences by repeat visits to the destination. An important share of this group members are 30 or above years old (43.5\%), who prefer to travel with their social groups, such as family members, friends, and relatives. In terms of socio-demographics, Single Regulars which represents $15.3 \%$ of the participants, show some similar characteristics of the Amateur Explorers. Exceptionally, the share of Turkish people (31.9\%) is the highest in this group, and family members are the main travel companions (46.8\%). The share of respondents who use television as the information source is higher than the other groups (12.8\%).

Table 6 here*

Table 7 here*

\section{Discussion and Theoretical Implications}


Given the increasing interest of holiday tourists in scuba diving, we wanted to understand which factors motivate them to participate in scuba diving during their holiday. In addition, inspired from previous segmentation studies conducted on different adventure tourism activities such as white water rafting (Albayrak \& Caber, 2018), we wanted to learn whether holiday tourists who participate scuba diving can be segmented based on their motivations. In order to address these research questions, we collected data from holiday tourists who participate in scuba diving in Kemer, Antalya-Turkey.

Study results revealed that holiday tourists were mostly pushed by exploration \& excitement to dive in a resort destination. This is an outcome in the line with Ong and Musa's (2012) opinions, who argue that 'exploring new things' and 'experiencing the adventure of diving' are the principal motivations of scuba divers. On the other hand, safety \& accessibility and new area were identified as the most important pull motivations for holiday tourists. In addition, the unspoiled diving destination pull motivation dimension, which contains the items related to area's quietness and un-crowded characteristics, is also important for tourists. This outcome shows similarity to Bentz et al.’s (2016) study in which an un-crowded diving area was found as an important pull motivation for the majority of tourists $(64.2 \%)$, irrespective of their specialization levels. These findings reflect that tourists who visited the Kemer area as a resort destination, were mostly 'pulled' by destination's ease of access and developed touristic facilities in spite of its relatively popular diving sites. Tourists also 'pushed' themselves to participate in scuba diving in the area for feeling the joy of the activity and learning new things about underwater life. To sum up, the results showed that Dann's (1977) Push and Pull Theory could be used for clarifying holiday tourists' scuba diving motivations. Hence, the present study has been one of the early research attempts in adapting this theory into this context.

Findings also showed that holiday tourists can be segmented based on their motivations to participate in scuba diving. Cluster analysis results suggested four groups (Enthusiastic Positivists, Youthful Hedonists, Amateur Explorers, and Single Regulars), who differ across their push and pull motivations. For example, while Enthusiastic Positivists are highly and almost equally motivated by all push and pull motivations, Youthful Hedonists seem to be mostly motivated by a specific push (exploration \& excitement) and pull (new area) motivation. Beside the motivations, socio-demographics, travelling and diving characteristics of the clusters were identified by additional analyses. In this way, both the groups' general profile and some other characteristics (like push-pull motivations and overall satisfaction with 
the activity) are explored and some comparisons with previous studies in the literature could be made, accordingly. For example, previous studies indicate that tourists' destination choices significantly differ according to their levels of scuba diving experience (Neto et al., 2017). Nevertheless, the findings of this research showed that tourists with different level of scuba diving experiences might have similar pull motivations in selecting a destination and could be grouped under the same market segment. Particularly this study sample, visiting a destination that is not renowned as a dive destination for experienced divers, was more homogenous than the global picture. The present study, therefore, contributes to the generalizability of previous segmentation researches on the motives of adventure tourism participants (Albayrak \& Caber, 2018). Taken together, this research shows that participants in adventure tourism are not homogeneous; even if they have been behaved as a single market segment.

\section{Managerial Implications}

The findings of this study have some practical and managerial implications for both destination managers and scuba diving companies. From the destination management pointof-view, such market segmentation focused researches may help the managers in generating tailor-made scuba diving services that sustain destination competitiveness and success against the others. In the case of Kemer, local authorities may try to base their destination strategies on the scientific studies' results which clearly show the general tourist characteristics, motivations, and perceptions. For example, findings of this study indicate that tourists who visit resort destinations tend to give importance to safety and accessibility issues as well as unspoiled characteristics of the diving areas. Tourists also look for exploration and excitement opportunities in a diving activity. Hence, destination authorities may attempt to promote the underwater richness of the diving areas in their marketing efforts and controlling the safety and security precautions followed in diving operations.

By taking into account the importance of the Internet as an information source especially for tourists who are named as Youthful Hedonists in this study, destination authorities are advised to design digital presence that contains all the required information about scuba diving in Kemer area (about underwater richness, safety and security precautions, diving companies, etc.). Such a practice can be beneficial for giving the basic information of scuba diving to tourists who are called as Amateur Explorers in this research, since an important percentage of this type of tourists have no previous diving experience. 
From the scuba diving companies’ perspectives, the findings show that diversified promotion messages should be supplied for different market segments to attract a greater number of tourists. For example, for tourists who are named as Single Regulars in this study, exploration is as important as socialisation in scuba diving. Therefore, promotional messages targeting to Single Regulars need to underline the availability of meeting new people with similar interests in scuba diving for motivating such tourists to attend this activity.

In general, a good diving experience may enhance the overall experience of holiday tourists at a destination. Since tourists increasingly seek to have active holiday experiences (Sung, 2004), scuba diving is an option for destination authorities and companies to meet these expectations. This paper also identifies the importance of new markets which are attracted to scuba diving tourism such as Russia, Turkey, and Ukraine. The experiential imperative of these markets is clear, but does present some potential managerial difficulties in terms of managing expectations.

\section{Limitations and Future Research Directions}

The present study provides important contributions that align tourism motivation literature with existing knowledge on scuba diving. It is novel in its segmentation of the new scuba diving tourist who is less likely to be committed to the activity, rather a mass tourist in search of a novel experience. However the study does have some limitations that must be pointed out for future research avenues. For example, the study results are specific to one mass scuba destination (Kemer, in Antalya-Turkey). Although this paper is among the first to specifically study casual divers, and will be useful as a point of reference for future studies, findings should be cautiously generalised to other destinations. Collecting data from just one scuba diving company’s customers can be seen another limitation of this study. In future studies, researchers are advised to use alternative research designs to obtain more representative results. In addition, future studies may attempt to compare the motivations of these holiday tourists and professional scuba divers. Comparison of the scuba diving motivations relying on the participants' experience levels and nationalities may offer a deeper insight into the motives behind the scuba divers' behaviours. This would give greater insight into the emerging markets for scuba diving tourism which this paper identifies. In particular, issues of sustainability in converting these new markets from 'tea bag' divers (whose experiences lack the emotional, cognitive, and normative potentials of scuba diving) to committed ocean ambassadors warrants further consideration. 


\section{References}

Albayrak, T., \& Caber, M. (2018). A motivation-based segmentation of holiday tourists participating in white-water rafting. Journal of Destination Marketing \& Management, 9, 64-71.

Barker, N. H., \& Roberts, C. M. (2004). Scuba diver behaviour and the management of diving impacts on coral reefs. Biological Conservation, 120(4), 481-489.

Beard, J. G., \& Ragheb, M. G. (1983). Measuring leisure motivation. Journal of Leisure Research, 15(3), 219-228.

Bentz, J., Lopes, F., Calado, H., \& Dearden, P. (2016). Managing marine wildlife tourism activities: Analysis of motivations and specialization levels of divers and whale watchers. Tourism Management Perspectives, 18, 74-83.

Bideci, C. and Cater, C (2020) In Search of Underwater Atmosphere: A New Diving World on Artificial Reefs. Chapter 17 in Volgger, M. and Pfister, D. (eds.) Atmospheric turn in tourism. Emerald.

Bradley, D., Papastamatiou, Y. P., \& Caselle, J. E. (2017). No persistent behavioural effects of SCUBA diving on reef sharks. Marine Ecology Progress Series, 567, 173-184.

Caber, M., \& Albayrak, T. (2016). Push or pull? Identifying rock climbing tourists' motivations. Tourism Management, 55, 74-84.

Cater, C. (2010). Any closer and you'd be lunch!: Interspecies interactions as nature tourism at marine aquaria. Journal of Ecotourism, 9(2), 133-148.

Cater, C. (2008). The life aquatic: Scuba diving and the experiential imperative. Journal of Tourism in Marine Environments, 5(4), 233-244.

Cater, C. and Cater, E. (2007) Marine Ecotourism: between the devil and the deep blue sea. CABI, Oxford.

CBI (2019). Dive tourism from Europe. Centre for the Promotion of Imports from Developing Countries. Retrieved from: https://www.cbi.eu/market-information/tourism/divetourism/europe/, in 19.10.2019 
Dailysabah news (2018). Retrieved from:

https://www.dailysabah.com/life/2018/04/25/southern-anatolia-new-hot-spot-for-divingtourism, in 10.01.2019.

Dann, G. (1977). Anomie, ego-enhancement and tourism. Annals of Tourism, 4(4), 184- 194.

Davis, D., \& Tisdell, C. (1995). Recreational scuba-diving and carrying capacity in marine protected areas. Ocean \& Coastal Management, 26(1), 19-40.

Dearden, P., Bennett, M., \& Rollins, R. (2006). Implications for coral reef conservation of diver specialization. Environmental Conservation, 33(4), 353-363.

Dimmock, K. (2009). Finding comfort in adventure: Experiences of recreational SCUBA divers. Leisure Studies, 28(3), 279-295.

Fuchs, G., Reichel, A., \& Shani, A. (2016). Scuba divers: the thrill of risk or the search for tranquility. Tourism Recreation Research, 41(2), 145-156.

Garcia, O. (2018). New dialogues with the Ocean as a recreational diver. PhD thesis, Aberystwyth University, Wales, UK.

Garrod, B., \& Gossling, S. (Eds.). (2008). New Frontiers in Marine Tourism. Diving Experiences, Sustainability \& Management. Routledge.

Hurriyet (2018). Retrieved from: http://www.hurriyet.com.tr/baskan-gul-kemere-1-5-milyonrus-turist-bekli-40776095, in 20.03.2019

Kemer Municipality (2019). Retrieved from: http://www.antalya-kemer.bel.tr/en-anasayfaicerik/about-kemer, in 17.01.2019

KETAV (2019). Retrieved from: http://www.ketav.org/index.php?goto=icerik\&cat_idx=19, in 17.01.2019

Kim, S. S., Lee, C. K., \& Klenosky, D. B. (2003). The influence of push and pull factors at Korean national parks. Tourism Management, 24(2), 169-180.

Kline, R. B. (2005). Principles and Practice of Structural Equation Modeling, 2nd edition, New York: Guilford Publications.

Lee, C. K., Yoon, Y. S., \& Lee, S. K. (2007). Investigating the relationships among perceived value, satisfaction, and recommendations: The case of the Korean DMZ. Tourism Management, 28(1), 204-214. 
Meisel-Lusby, C., \& Cottrell, S. (2008). Understanding motivations and expectations of scuba divers. Tourism in Marine Environments, 5(1), 1-14.

Morgan, D., Moore, K., \& Mansell, R. (2005). Adventure tourists on water: Linking expectations, affect, achievement and enjoyment to the sports tourism adventure. Journal of Sport Tourism, 10(1), 73-88.

Musa, G., \& Dimmock, K. (2012). Scuba diving tourism: Introduction to the special issue. Tourism in Marine Environments, 8(1-2), 1-5.

Musa, G., Kadir, S. L. S. A., \& Lee, L. (2006). Layang Layang: An empirical study on scuba divers' satisfaction. Tourism in Marine Environments, 2(2), 89-102.

Neto, A. Q., Lohmann, G., Scott, N., \& Dimmock, K. (2017). Rethinking competitiveness: Important attributes for a successful scuba diving destination. Tourism Recreation Research, 42(3), 356-366.

National Oceanic and Atmospheric Administration (NOAA). (2019). Tourism and recreation. Retrieved from https://coast.noaa.gov/states/fast-facts/tourism-and-recreation.html (Access Date: 24.10.2019)

NRW (2017). Skomer Marine Conservation Zone Annual Report 2017. Natural Resources Wales.

Ong, T. F., \& Musa, G. (2012). Examining the influences of experience, personality and attitude on SCUBA divers' underwater behaviour: A structural equation model. Tourism Management, 33(6), 1521-1534.

PADI (2019). Professional Association of Diving Instructors 2019 Worldwide Corporate Statistics. Retrieved from: https://www.padi.com/corporate/company-info, in 12.03.2019

Rice, K. (1987). Special Report: SCUBA diving: Dive market requires specialized skill and information. Tour and Travel News, (February 9), 24-27.

Sung, H. H. (2004). Classification of adventure travelers: Behavior, decision making, and target market. Journal of Travel Research, 42, 343-356.

Taylor, D. McD., O’Toole, K. S., \& Ryan, C. M. (2003). Experienced scuba divers in Australia and the United States suffer considerable injury and morbidity. Wilderness and Environmental Medicine, 14, 83-88. 
Todd, S. L., Graefe, A. R., \& Mann, W. (2002). Differences in SCUBA diver motivations based on level of development. In: Todd, S., (Ed.) Proceedings of the 2001 Northeastern Recreation Research Symposium. Gen. Tech. Rep. NE-289. Newtown Square, PA: US Department of Agriculture, Forest Service, Northeastern Research Station. 107-114. (Vol. 289).

Turkish Chamber of Shipping, Antalya Branch (2018). Underwater Sculpture Museum was created in Kemer at Hurriyet News, Retrieved from: http://www.hurriyet.com.tr/yerelhaberler/antalya/kemerde-sualti-heykel-muzesi-olusturuldu-40960133, in 13.02.2019

Wilks, J., \& Davis, R. J. (2000). Risk management for scuba diving operators on Australia's Great Barrier Reef. Tourism Management, 21, 591-599.

Wong, K., Thirumoorthy, T., \& Musa, G. (2013). Scuba diving motivation. In: Musa, G., \& Dimmock, K. (Eds.) Scuba Diving Tourism. Routledge.

Woratschek, H., Hannich, F. M., \& Ritchie, B. (2007). Motivations of sports tourists: An empirical analysis in several European rock climbing regions. Retrieved from: http://www.fiwi.uni-bayreuth.de/de/download/WP_02-07.pdf, in 15.06.2018

WTO (2001). Tourism 2020 Vision. Vol.7 Global Forecasts and profiles of market segments. Madrid:WTO. 